\title{
Factors associated with the development of early childhood caries among Brazilian preschoolers
}

\author{
Patrícia Corrêa-Faria(a) \\ Paulo Antônio Martins-Júnior ${ }^{(a)}$ \\ Raquel Gonçalves Vieira- \\ Andrade (b) \\ Leandro Silva Marques(c) \\ Maria Letícia Ramos-Jorge(a) \\ (a) Department of Pediatric Dentistry, Faculty \\ of Dentistry, Univ Federal dos Vales \\ do Jequitinhonha e Mucuri - UFVJM, \\ Diamantina, MG, Brazil. \\ (b) Department of Orthodontics and Pediatric \\ Dentistry, Faculty of Dentistry, Univ Federal \\ de Minas Gerais - UFMG, Belo Horizonte, \\ MG, Brazil. \\ (c) Department of Dentistry, Faculty of \\ Dentistry, Univ Federal dos Vales do \\ Jequitinhonha e Mucuri - UFVJM, \\ Diamantina, MG, Brazil.
}

\begin{abstract}
The aim of this study was to assess the prevalence of early childhood caries (ECC) in children and investigate the influence of sociodemographic variables, quality of oral hygiene and child-related aspects. A cross-sectional study was carried out with 593 children aged three to five years. Data were collected through clinical examinations and interviews with parents. Interviews with parents of the children were conducted to acquire information on sociodemographic aspects, breastfeeding, bottle feeding and harmful oral habits. Statistical analysis involved the chi-square test and the Poisson regression. The prevalence of ECC was $53.6 \%$. The occurrence of ECC was greater among children with unsatisfactory oral hygiene (PR: 2.95; 95\% CI: 2.42-3.60) and those from a family with a lower monthly household income (PR: 1.62; 95\% CI: 1.24-2.10). In conclusion, unsatisfactory oral hygiene and monthly income exerted an influence on the occurrence of ECC among preschoolers.
\end{abstract}

Descriptors: Dental Caries; Epidemiology; Child, Preschool.

\section{Introduction}

Early childhood caries (ECC) is one of the most prevalent chronic conditions among children, and exerts a negative impact on the quality of life of both the child and the family., The prevalence rate of ECC varies in different populations, due partially to socioeconomic differences, which lead to inequalities in the distribution of wealth, in the availability of technological advances and in access to both education and healthcare services. ${ }^{3}$ According to a national survey carried out in Brazil, $53.4 \%$ of five-year-old children had an average of 2.3 teeth with caries in 2010, and approximately $80.0 \%$ of these cases were untreated. ${ }^{4}$

Studies have found that the frequency of ECC is greater among children in families with a larger number of siblings ${ }^{5}$ and those whose mothers are younger. ${ }^{6}$ Moreover, factors related to the family, such as parents' schooling and monthly household income, are related to a greater dental caries prevalence rate. ${ }^{78}$ According to the literature, young parent age, a low level of education and insufficient knowledge regarding oral health may lead to a greater prevalence of ECC among children. ${ }^{5,6,9}$ Children from families with a lower income may also have a greater dental caries experience. ${ }^{10,11}$

Insofar as dental caries may be more frequent in groups with a low-
Submitted: Feb 20, 2013

Accepted for publication: Apr 29, 2013

Last revision: May 18, 2013
Corresponding Author:

Patrícia Corrêa-Faria

E-mail: patriciafaria.faria09@gmail.com 
er socioeconomic status, and the prevalence of this condition is high among Brazilian preschoolers, it is necessary to determine the prevalence and distribution of this condition in this population, to enable the establishment of appropriate preventive measures, including the education and motivation of the nuclear family. These data are important, because preschool children are not covered by public health programs, thus subjecting young children to suffering chronic pain and discomfort. ${ }^{12}$

With this in mind, the aim of this study was to assess the prevalence of ECC in children aged three to five years, and investigate the influence of sociodemographic variables, quality of oral hygiene and child-related aspects.

\section{Methodology}

A cross-sectional study was carried out in the city of Diamantina, located in the northern part of the state of Minas Gerais, in southeastern Brazil. The human development index for the city is $0.748 .{ }^{13}$ According to the last census of the Instituto Brasileiro de Geografia e Estatística (IBGE), ${ }^{14}$ Diamantina has a population of 45,880 inhabitants, 2,992 of whom are children aged 0 to four years. The study population included children from three to five years of age treated at the ten basic healthcare units in the city during immunization campaigns held in 2010.

A $44.8 \%$ prevalence rate for caries in the deciduous dentition, ${ }^{15}$ a $95 \%$ confidence interval and a $5 \%$ standard error were considered in calculating the sample size, establishing a minimum sample of 380 children. A correction factor of 1.2 was applied to enhance the precision ( $\mathrm{n}=456$ children), and an additional 92 individuals were added to compensate for possible losses, totaling a sample of 548 children. Systematic sampling was adopted for the purpose of randomization, for which purpose the children were arranged in a line; the first child was examined, the second was not, the third child was examined, and so on.

Data acquisition involved an oral clinical exam, anthropometric measures and a questionnaire administered in interview form to acquire information on family structure (number of children, parents' age and place of residence) and sociodemographic aspects (monthly household income and parents' schooling). A team made up of three researchers (an examiner and two assistants) was installed at each healthcare unit.

Prior to the fieldwork, the examiners underwent a calibration and training exercise for the diagnosis of early childhood caries. Calibration was performed using images of different clinical situations on two separate occasions with a one-week interval between sessions. Minimum intraexaminer agreement was 0.81 and minimum interexaminer agreement was 0.80 .

During the exam, the child remained seated in a chair in front of the examiner and facing a window, to make maximum use of natural light. The criteria of the World Health Organization (WHO) were used for the diagnosis of dental caries. ${ }^{16}$ ECC was dichotomized as absent or present. Oral hygiene quality was evaluated based on the presence of visible plaque. The tooth surfaces were scraped with a clinical probe, and the presence of plaque indicated unsatisfactory oral hygiene.

The children were weighed on a digital scale (Plenna, São Paulo, Brazil). The scale was calibrated using an object of known weight. Stature was determined on a stadiometer with a millimeter scale and two-meter maximum height (Welmy, Porto Alegre, Brazil), placed on a flat surface. The researchers who measured the children's stature underwent a training process prior to and during the data collection. The examiners measured stature and body mass on two separate occasions with a 15-day interval between readings to determine intraexaminer and interexaminer reliability using the intraclass correlation coefficient (ICC: 0.86). Nutritional status was determined through comparisons made with the reference standards stipulated by the American National Center for Health Statistics (NCHS). ${ }^{17}$

Birth information was obtained from the vaccination card of each child. The children were classified based on the WHO criteria:

- very low birth weight (less than $1500 \mathrm{~g}$ ),

- low birth weight (less than $2500 \mathrm{~g}$ ) and

- normal birth weight (equal to or greater than $2500 \mathrm{~g}) .^{18}$ 
Information on the child's age, sex, any harmful oral habits, bottle feeding, breastfeeding and gestational age was also acquired through interviews with parents. The parents were asked if the child had any harmful oral habits (pacifier sucking, finger sucking and biting on objects) at the time of the study. Gestational age was classified as "full term" (37 or more weeks of gestation) or "premature birth" (less than 37 weeks of gestation). ${ }^{18}$

Data analysis was performed using the Statistical Package for Social Sciences (SPSS for Windows, version 17.0, SPSS Inc., Chicago, USA). Associations between ECC and independent variables were determined using the chi-square test. Poisson regression with robust variance was performed for the analysis of factors associated with ECC. The magnitude of the association of each factor with ECC was assessed using non-adjusted and adjusted prevalence ratios (PR), respective $95 \%$ confidence intervals $(\mathrm{CI})$ and p-values (Wald test). Explanatory variables with a $p$-value of $\leq 0.25$ in the bivariate analysis were incorporated into the model.

This study received the approval of the Human Research Ethics Committee (register 077/09) of the Universidade Federal dos Vales do Jequitinhonha e Mucuri, Brazil.

\section{Results}

Five hundred and ninety-three preschool children were evaluated. Mean age was 51.93 months (standard deviation: 9.24 months). The female gender accounted for $52.4 \%(\mathrm{n}=311)$ of the sample. The prevalence of early childhood caries was $53.6 \%$ $(\mathrm{n}=318)$.

ECC experience was expressed as present/absent, and comparisons were made in relation to the characteristics of the children. ECC was significantly associated with age $(\mathrm{p}=0.014)$, duration of breastfeeding $(\mathrm{p}=0.014)$ and oral hygiene $(\mathrm{p}<0.001 ; \mathrm{Ta}-$ ble 1$)$.

ECC was significantly associated with place of residence $(p=0.004)$, mother's schooling $(\mathrm{p}<0.001)$, father's schooling $(\mathrm{p}=0.001)$, number of children in the family ( $\mathrm{p}=0.032$ ) and monthly household income $(\mathrm{p}<0.001$; Table 2$)$.

In the adjusted multivariate regression model,
Table 1 - Distribution of ECC according to aspects related to the child. (continued on next page)

\begin{tabular}{|c|c|c|c|}
\hline & \multicolumn{2}{|c|}{ ECC } & \multirow[b]{2}{*}{ p-value } \\
\hline & $\begin{array}{c}\text { No } \\
\mathrm{n}(\%)\end{array}$ & $\begin{array}{c}\text { Yes } \\
\text { n (\%) }\end{array}$ & \\
\hline \multicolumn{4}{|l|}{ Sex } \\
\hline Male & $128(45.4)$ & $154(54.6)$ & \\
\hline Female & $147(47.3)$ & $164(52.7)$ & $0.680^{*}$ \\
\hline \multicolumn{4}{|l|}{ Age (years) } \\
\hline 3 & $91(52.0)$ & $84(48.0)$ & \\
\hline 4 & $134(47.2)$ & $150(52.8)$ & \\
\hline 5 & $50(37.3)$ & $84(62.7)$ & $0.014^{* *}$ \\
\hline \multicolumn{4}{|l|}{ Birth weight } \\
\hline Very low & $0(0.0)$ & $3(100.0)$ & \\
\hline Low & $30(55.6)$ & $24(44.4)$ & \\
\hline Normal & $240(46.1)$ & $281(53.9)$ & $0.698^{* *}$ \\
\hline \multicolumn{4}{|l|}{ Breastfeeding } \\
\hline No & $21(50.0)$ & $21(50.0)$ & \\
\hline Yes & $252(46.2)$ & $294(53.8)$ & $0.749^{*}$ \\
\hline \multicolumn{4}{|l|}{ Bottle feeding } \\
\hline No & $105(43.7)$ & $135(56.3)$ & \\
\hline Yes & $168(48.4)$ & $179(51.6)$ & $0.275^{*}$ \\
\hline \multicolumn{4}{|c|}{ Duration of breastfeeding (months) } \\
\hline$<6$ & $74(51.4)$ & $70(48.6)$ & \\
\hline 6 to 12 & $89(52.3)$ & $81(47.7)$ & \\
\hline$>12$ & $108(40.0)$ & $162(60.0)$ & $0.014^{* *}$ \\
\hline \multicolumn{4}{|c|}{ Duration of bottle feeding (months) } \\
\hline$<26$ & $80(45.9)$ & $94(54.1)$ & \\
\hline$>26$ & $86(50.2)$ & $85(49.8)$ & $0.452^{*}$ \\
\hline \multicolumn{4}{|c|}{ Harmful oral habits } \\
\hline No & $159(37.4)$ & $183(62.6)$ & \\
\hline Yes & $116(46.4)$ & $134(53.6)$ & $1.0^{*}$ \\
\hline \multicolumn{4}{|c|}{ Nonnutritive sucking habits } \\
\hline No & $222(45.5)$ & $266(54.5)$ & \\
\hline Yes & $53(51.0)$ & $51(49.0)$ & $0.331^{*}$ \\
\hline \multicolumn{4}{|l|}{ Oral hygiene } \\
\hline Satisfactory & $218(73.6)$ & $78(26.4)$ & \\
\hline Unsatisfactory & $52(18.0)$ & $238(82.0)$ & $<0.001^{*}$ \\
\hline
\end{tabular}

oral hygiene (PR: 2.95; 95\% CI: 2.42-3.60) and monthly household income (PR: 1.62; 95\% CI: 1.24-2.10) remained associated with a greater prevalence rate of ECC, regardless of the other variables 
Table 1 - (continued)

\begin{tabular}{|c|c|c|c|}
\hline & \multicolumn{2}{|c|}{ ECC } & \multirow[b]{2}{*}{$\mathrm{p}$-value } \\
\hline & $\begin{array}{c}\text { No } \\
\text { n (\%) }\end{array}$ & $\begin{array}{c}\text { Yes } \\
\text { n (\%) }\end{array}$ & \\
\hline \multicolumn{4}{|l|}{ Nutritional status } \\
\hline Ideal range & $208(44.9)$ & $255(55.1)$ & \\
\hline Overweight/obesity & $35(61.4)$ & $22(38.6)$ & \\
\hline Nutritional risk & $21(46.7)$ & $24(53.3)$ & \\
\hline Underweight & $7(50.0)$ & $7(50.0)$ & \\
\hline Very underweight & $1(12.5)$ & $7(87.5)$ & $1.0^{* *}$ \\
\hline
\end{tabular}

(age, duration of breastfeeding, place of residence, parents' schooling, number of children in the family, and mother's age at the birth of the child; Table 3).

\section{Discussion}

Children with unsatisfactory oral hygiene and those from low-income families had a greater frequency of ECC. ECC was found in the majority of children examined (53.6\%). This prevalence rate is similar to that reported in a Brazilian epidemiological study carried out in 2010, which reports a $54.3 \%$ frequency of ECC. ${ }^{4}$ The present study was carried out in a region of Brazil with a Human Development Index of $0.748,{ }^{13}$ indicative of low levels of social and economic development. Thus, the present findings confirm previous reports of a high frequency of ECC among children in regions with low levels of socioeconomic development. ${ }^{3,19}$

Adequate oral hygiene is one of the requisites for preventing ECC. However, the majority of the children in the present study exhibited poor oral hygiene, characterized by the presence of clinically visible plaque. Recent studies have also found an association between dental caries and supervision during brushing, and have concluded that preschoolers do not yet have the manual dexterity needed for the maintenance of adequate oral hygiene. ${ }^{20,21}$ While supervision during brushing was not analyzed in the present study, the high prevalence of unsatisfactory oral hygiene may be explained by a lack of accompaniment by parents during tooth brushing, or else unawareness on the part of parents regarding ad-
Table 2 - Distribution of ECC according to mother- and family-related aspects.

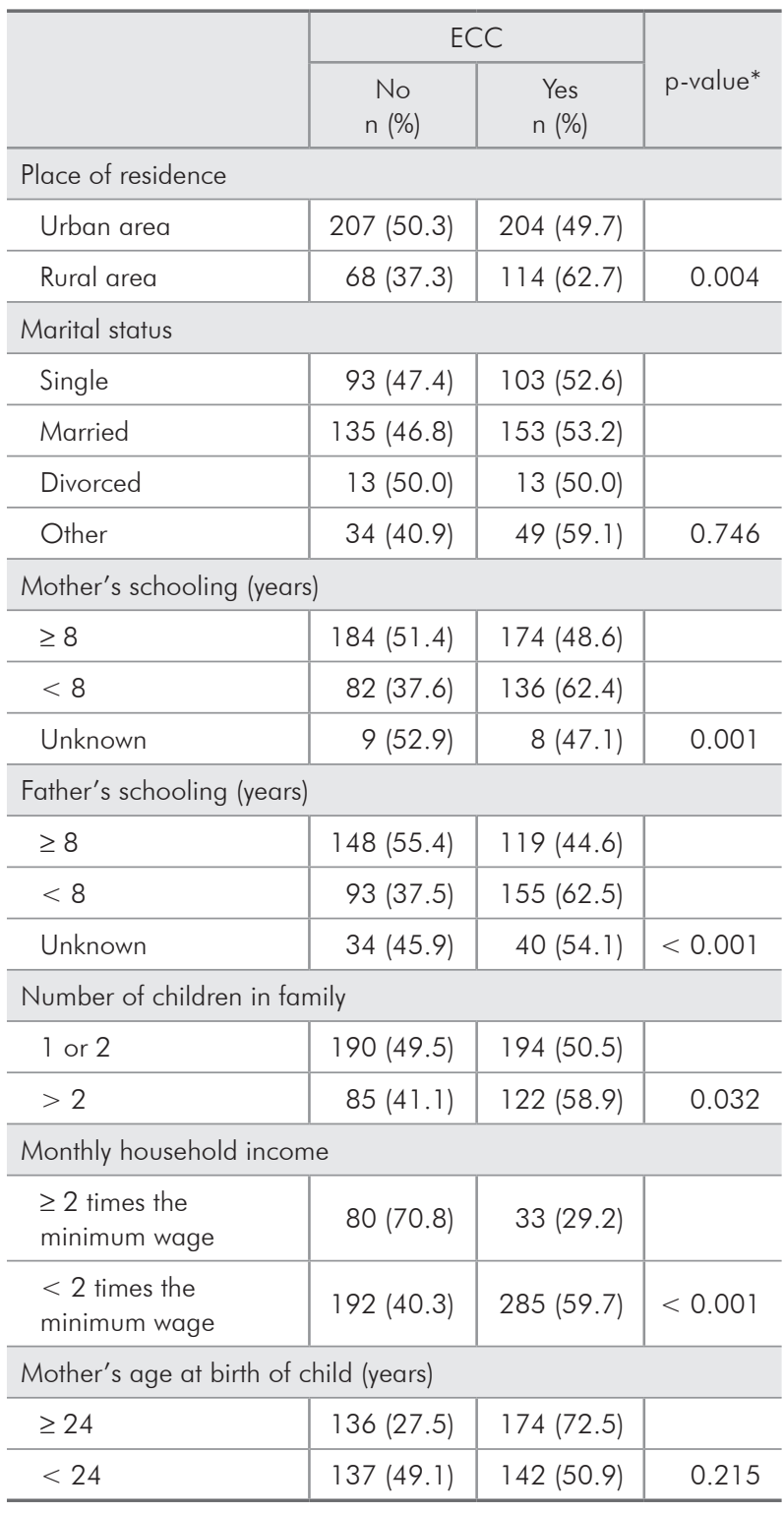

* Pearson's chi-square test $(p<0.05)$.

equate oral hygiene practices.

A greater frequency of ECC was found among children from families with a lower household income. ${ }^{22}$ In contrast, a study involving Chinese children reports an association between dental caries and a higher monthly income. ${ }^{23}$ However, the comparison between the two studies is limited by methodological differences, such as the study design and the method for evaluating ECC. Monthly household income is directly related to other sociodemographic 
Table 3 - Prevalence ratios and confidence intervals for associations between ECC and associated variables $(p<0.05)$.

\begin{tabular}{|c|c|c|c|c|c|c|}
\hline Variable & $\begin{array}{c}\text { Prevalence ratio } \\
\text { (unadjusted) }\end{array}$ & $95 \% \mathrm{Cl}$ & $p$ & $\begin{array}{c}\text { Prevalence ratio } \\
\text { (adjusted) }\end{array}$ & $95 \% \mathrm{Cl}$ & $p$ \\
\hline \multicolumn{7}{|l|}{ Oral hygiene } \\
\hline Satisfactory & - & - & - & - & - & - \\
\hline Unsatisfactory & 3.11 & $2.55-3.79$ & $<0.001$ & 2.95 & $2.42-3.60$ & $<0.001$ \\
\hline \multicolumn{7}{|l|}{ Monthly household income } \\
\hline$\leq 2$ times the minimum wage & - & - & - & - & - & - \\
\hline$<2$ times the minimum wage & 2.04 & $1.52-2.75$ & $<0.001$ & 1.62 & $1.24-2.10$ & $<0.001$ \\
\hline
\end{tabular}

aspects reported to be associated with ECC. Low household income is associated with the level of the parents' schooling, access to information regarding health, and access to healthcare services. Inadequate perceptions are also reported regarding the maintenance of a child's oral health, as well as the need to use dental services and to have healthy eating and hygiene habits. ${ }^{20}$

Children who resided in rural areas had a greater frequency of ECC in comparison to those residing in urban areas. A study involving rural communities in Mexico reports similar results. ${ }^{24}$ Isolation from urban centers, restricted or inadequate knowledge regarding oral health care and inefficient bacterial control practices seem to explain the high levels of ECC among children residing in rural areas. ${ }^{25}$

A low parent schooling level may imply insufficient knowledge regarding oral health, and a consequently greater number of caries in children. ${ }^{5,6,9}$ The present study also analyzed the schooling of fathers, differing from most studies, in which only the association between the mother's schooling and ECC is addressed. The evaluation of the father's schooling is important, insofar as both parents have currently become the main caregivers and educators of their children.

Family size also exerts an influence on the occurrence of ECC. ${ }^{5}$ In agreement with this statement, the children in the present study-the families of whom were made up of more than two childrenhad a greater frequency of ECC. ${ }^{22}$ Children require special attention and care in terms of oral health. In larger families, the attention given by parents is shared among the children. This may result in a greater number of ECC, because of the lack of in- dividualized monitoring. ${ }^{5}$ Thus, this association of family size to occurrence of ECC could explain the reduction in oral health care levels resulting from the need for parents to divide their attention among all family members.

In terms of child-attributed factors, the prevalence of ECC was associated with age, duration of breastfeeding and oral hygiene. A tendency was found regarding a greater prevalence of ECC associated with an increase in age, and with caries being more common among the five-year-olds, in agreement with findings reported in previous studies. ${ }^{20,26}$ This result can be explained by the change in the dietary habits and hygiene practices in older children. ${ }^{26}$

A prolonged period of breastfeeding was also significantly associated with ECC. However, a longitudinal study involving preschoolers found that prolonged breastfeeding was not a risk factor for ECC, whereas other factors, such as age and high sugar intake, were associated with the occurrence of dental caries. ${ }^{27}$ Thus, caution should be exercised when interpreting the association between the duration of breastfeeding and ECC in the present study, insofar as this finding may have been influenced by other variables, such as sugar intake, which was not evaluated. Moreover, one may hypothesize that this association is related to the absence of adequate oral hygiene after breastfeeding, or a delay in starting oral hygiene practices and a lack of parental assistance during tooth brushing ${ }^{28}$ which contributes directly to poor oral hygiene. This hypothesis should be investigated in studies addressing the quality of children's oral hygiene as performed by parents' after the breastfeeding period, as well as parents' knowledge of their children's oral health. 
The present study has limitations that should be addressed. The cross-sectional design does not allow the evaluation of causality. Moreover, memory bias may have occurred on the part of parents, regarding aspects related to the first year of the child's life, such as the duration of breastfeeding.

The findings of the present study demonstrate that ECC continues to affect a large portion of preschoolers and is related to familial and socioeconomic aspects, as well as factors inherent to the child. The family context is related to the ability to care for a child in terms of emotional and physical

\section{References}

1. Abanto J, Carvalho TS, Mendes FM, Wanderley MT, Bönecker M, Raggio DP. Impact of oral diseases and disorders on oral health-related quality of life of preschool children. Community Dent Oral Epidemiol. 2011 Apr;39(2):105-14.

2. Martins-Júnior PA, Vieira-Andrade RG, Corrêa-Faria P, Oliveira-Ferreira F, Marques LS, Ramos-Jorge ML. Impact of early childhood caries on the oral health-related quality of life of preschool children and their parents. Caries Res. 2013 Dec;47(3):211-8.

3. Do LG. Distribution of caries in children: variations between and within populations. J Dent Res. 2012 Jun;91(6):536-43.

4. Brasil. Ministério da Saúde. Projeto SB Brasil 2010: nota para a imprensa. Brasília (DF): Ministério da Saúde; 2010 [cited 2013 May 29]. Available from: http://www.idisa.org.br/img/ File/SAUDE\%20BUCAL--NotaParaImprensa-28dez2010\%20 $\% 282 \% 29$.pdf.

5. Wellappuli N, Amarasena N. Influence of family structure on dental caries experience of preschool children in Sri Lanka. Caries Res. 2012 Apr;46(3):208-12.

6. Niji R, Arita K, Abe Y, Lucas ME, Nishino M, Mitome M. Maternal age at birth and other risk factors in early childhood caries. Pediatr Dent. 2010 Nov-Dec;32(7):493-8.

7. Wigen TI, Wang NJ. Maternal health and lifestyle, and caries experience in preschool children. A longitudinal study from pregnancy to age 5 yr. Eur J Oral Sci. 2011 Dec;119(6):463-8.

8. Paula JS, Leite IC, Almeida AB, Ambrosano GM, Mialhe FL. The impact of socioenvironmental characteristics on domains of oral health-related quality of life in Brazilian schoolchildren. BMC Oral Health. [Internet] 2013 Jan 28 [cited 2013 May 29];13(10):1-8. Available from: http://www. biomedcentral.com/content/pdf/1472-6831-13-10.pdf. doi; 10.1186/1472-6831-13-10.

9. Tiberia MJ, Milnes AR, Feigal RJ, Morley KR, Richardson DS, Croft WG, et al. Risk factors for early childhood caries in Canadian preschool children seeking care. Pediatr Dent. 2007 May-Jun;29(3):201-8. aspects, including oral health care. Insofar as ECC is a preventable condition, it is fundamental to identify children and families exposed to the aforementioned factors and include these aspects in drawing up and implementing preventive and curative actions aimed at reducing the prevalence of oral disease, and providing a better quality of life.

\section{Conclusion}

The prevalence of ECC was high and was associated with both poor oral hygiene and lower monthly household income.

10. Harris R, Nicoll AD, Adair PM, Pine CM. Risk factors for dental caries in young children: a systematic review of the literature. Community Dent Health. 2004 Mar;21(1 Suppl):71-85.

11. Oliveira LB, Sheiham A, Bönecker M. Exploring the association of dental caries with social factors and nutritional status in Brazilian preschool children. Eur J Oral Sci. 2008 Feb;116(1):37-43.

12. Lee GH, McGrath C, Yiu CK, King NM. A comparison of a generic and oral health-specific measure in assessing the impact of early childhood caries on quality of life. Community Dent Oral Epidemiol. 2010 Aug;38(4):333-9.

13. Programa das Nações Unidas para o Desenvolvimento. Atlas de Desenvolvimento Humano no Brasil [Internet]. Brasília (DF): ONU; 2003 [cited 2013 May 29]. Available from: http://www.pnud.org.br/atlas/ranking/IDH_Municipios_Brasil_2000.aspx?indiceAccordion = 1\&li=li_Ranking2003

14. Instituto Brasileiro de Geografia e Estatística [Internet]. Brasília (DF): IBGE; 2010 [cited 2013 May 29]. Available from: http://www.ibge.gov.br/cidadesat/topwindow.htm?1.

15. Nogueira LC, Resende NFB, Ferraz NKL, Corrêa-Faria P, Marques LS, Ramos-Jorge ML. Prevalence of dental caries in children aged 6 to 60 months and associated factors in Diamantina, Minas Gerais, Brazil. Pesqui Bras Odontoped Clin Integr (João Pessoa). 2012 Jan-Mar;12(1):13-7. Portuguese.

16. World Health Organization. Oral Health Surveys: basic methods. 4th. ed. Geneva: World Health Organization; 1997. Available from: http://www2.paho.org/hq/dmdocuments/2009/ OH_st_Esurv.pdf.

17. Hamill PVV, Drizd TA, Johnson CL, Reed RB, Roche AF, Moore WM. Physical growth: National Center for Health Statistical percentiles. Am J Clin Nutr. 1979 Mar;32(3):607-29.

18. Puffer RR, Serrano C. Patterns of Birth Weight. Washington, DC: PAHO, 1987. (Scientific Publication, 504).

19. Costa LR, Daher A, Queiroz MG. Early childhood caries and body mass index in young children from low income families. Int J Environ Res Public Health. 2013 Mar 5;10(3):867-78. 
- Factors associated with the development of early childhood caries among Brazilian preschoolers

20. Subramaniam P, Prashanth P. Prevalence of early childhood caries in 8-48 month old preschool children of Bangalore city, South India. Contemp Clin Dent. 2012 Jan;3(1):15-21.

21. Tinanoff N, Kanellis MJ, Vargas CM. Current understanding of the epidemiology mechanisms, and prevention of dental caries in preschool children. Pediatr Dent. 2002 NovDec;24(6):543-51.

22. Schroth RJ, Cheba V. Determining the prevalence and risk factors for early childhood caries in a community dental health clinic. Pediatr Dent. 2007 Sep-Oct;29(5):387-96.

23. Zhou Y, Yang JY, Lo EC, Lin HC. The contribution of life course determinants to early childhood caries: a 2-year cohort study. Caries Res. 2012 Apr;46(2):87-94.

24. Irigoyen ME, Luengas IF, Yashine A, Mejía AM, Maupomé G. Dental caries experience in Mexican schoolchildren from rural and urban communities. Int Dent J. 2000 Feb;50(1):41-5.
25. Silva RH, Castro RF, Cunha DC, Almeida CT, Bastos JR, Camargo LM. Dental caries in a riverine community in Rondônia State, Amazon Region, Brazil, 2005-2006. Cad Saude Publica. 2008 Oct;24(10):2347-53. Portuguese.

26. Hallet KB, O'Rourke PK. Social and behavioural determinants of early childhood caries. Aust Dent J. 2003 Mar;48(1):27-33.

27. Nunes AM, Alves CM, Araújo FB, Ortiz TM, Ribeiro MR, Silva AA, et al. Association between prolonged breast-feeding and early childhood caries: a hierarchical approach. Community Dent Oral Epidemiol. 2012 Dec;40(6):542-9.

28. Jose B, King NM. Early childhood caries lesions in preschool children in Kerala, India. Pediatr Dent. 2003 NovDec;25(6):594-600. 